\title{
Reliability Assessment on Pile Foundation Bearing Capacity Based on the First Four Moments in High-Order Moment Method
}

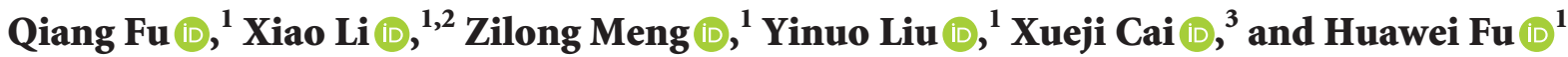 \\ ${ }^{1}$ School of Civil Engineering, Central South University, Changsha, Hunan 410075, China \\ ${ }^{2}$ National Engineering Laboratory for High Speed Railway Construction, 22 Shaoshan Road, Changsha 410075, China \\ ${ }^{3}$ School of Architectural Engineering, Sanming University, Sanming, Fujian 365004, China \\ Correspondence should be addressed to Zilong Meng; mzl_post@163.com
}

Received 20 October 2021; Accepted 5 November 2021; Published 16 December 2021

Academic Editor: Xuepeng Zhang

Copyright (C) 2021 Qiang Fu et al. This is an open access article distributed under the Creative Commons Attribution License, which permits unrestricted use, distribution, and reproduction in any medium, provided the original work is properly cited.

In this paper, the high-order moment method (HOMM) was developed for estimating pile foundation bearing capacity reliability assessment. Firstly, after the performance function was established, the first four moments (viz. mean, variance, skewness, and kurtosis) were suggested to be determined by a point estimate method based on two-dimensional reduction integrations. Then, the probability distribution of the performance function for the pile foundation bearing capacity was then approximated by a fourparameter cubic normal distribution, in which its distribution parameters are the first four moments. Meanwhile, the quantile of the probability distribution for the performance function and its reliability index was capable to be obtained through this distribution. In order to examine the efficiency of this method in engineering application, four pile foundations with different length-diameter radios were investigated in detail. The results demonstrate that the reliability analysis based on HOMM is greatly improved to the computational efficiency without loss precision compared with Monte Carlo simulation (MCS) and does not require complex partial derivative solving, checking point sought, and large numbers of iteration comparing with first-order reliability method (FORM). Moreover, the probability distribution function (PDF) approximated by the four-parameter cubic normal distribution was found to be consistent with that obtained by MCS. Eventually, the effects of parameter sensitivity for relative soil layer of the certain pile on reliability index were illustrated using the above-mentioned method. It indicated that the HOMM is an effective and simple approach for reliability assessment of the pile foundation bearing capacity.

\section{Introduction}

In decades, pile foundation is widely adopted in high-rise buildings and long-span bridge structures. Specifically, the pile foundation is with a series of advantages such as high bearing capacity, low settlement, easy construction, and so on $[1,2]$. However, although it plays a significant role in relevant structures, the reliability problems of bearing capacity for pile foundation have drawn much focuses in the engineering field due to its crucial role in structure safety and life control. In general, the main challenges for the reliability problems involved with the bearing capacity of pile foundation are caused by the uncertainties that existed in the relative geotechnical environment (viz. randomness, fuzziness and knowledge incompleteness) [3-6].
To date, much effort has been put into it by researchers, and lots of celebrated works can be traced towards this topic. Tandijiria et al. [7] performed a reliability analysis for the bearing capacity of the single pile subjected to horizontal loads, in detail; in their research, the failure probability of the bearing capacity under certain functions and the effects caused by the failure probability on relevant parameters are determined by implementing the response surface method (RSM). Zhao et al. [8] conducted the reliability analysis for pile under inclined load and proposed an approach that combined with the higher-order response surface function and RSM to investigate the relevant implicit performance functions. Li and Li [9] proposed an approach by combining the total probability theory and FORM to analyze the effects of pile bottom sediment on the reliability of bearing capacity 
for the single pile. Then, $\mathrm{Li}[10]$ adopted the FORM to analyze the reliability of bearing capacity for a single pile by redefining the deviation coefficient of the failure criterion. Chan and Low [11] focused on the nonlinear behavior of the computational models for soil and pile and determined relevant reliability indexes of piles under horizontal load in hard clay by combining certain optimization methods and RSM. Specifically, in this research, both the deformation failure mode and the bending failure modes were being taken into account. Moreover, Babu and Basha [12, 13] focused on the single anchored sheet pile wall in the sand and calculated the relevant reliability indexes for its bearing capacity by using FORM. In their research, the effects on corresponding reliability indexes caused by a series of parameters such as filling characteristics have been carefully examined. Kwak et al. [14] utilized the updated data obtained by Bayesian statistics theory and predicted relevant reliability indexes for driven steel pipe piles. Teixeira et al. [15] examined the influence of geotechnical uncertainties on the reliability of vertically loaded pile foundations by using MCS and FORM and conducted a reliability sensitivity analysis to the source of these uncertainties. Yoon et al. [16] explored practical implications of reliability analysis for the mono-pile foundation of an offshore wind turbine by RSM and MCS and investigated the sensitivities of mono-pile design parameters. Kawa et al. [17] dealt with reliability analysis of cantilever sheet pile wall located in noncohesive soil with random properties by utilizing MCS technique, and the probability distributions of the results for different values of vertical and horizontal scales of fluctuation are obtained. Chanda et al. [18] assessed the influence of shear strength variability of soil on seismic response of pile foundation considering soil nonlinearity by MCS and inferred the importance of shear strength variability of soil on increase in the percentage of steel requirement in pile foundation. $\mathrm{Xu}$ et al. [19] proposed a modified reliability optimizing calculation approach based on the center point method of FORM, which is capable of simplifying the nonlinear iteration procedure during relative calculation. Cai et al. [20] adopted the HOMM based on one-dimensional reduction integration and three-parameters lognormal distribution, which parameters are the first three moments of performance function to calculate the reliability indexes of the bearing capacity for pile foundation.

Among the above-mentioned researches, it can be concluded that for the reliability analysis of pile foundation, utilization of four methods, namely, MCS, FORM, RSM, and HOMM emerged at a comparatively high frequency for relevant researchers. However, for FORM, it is usually required complex partial derivative solving, checking points sought, and large numbers of iteration. In addition, in real engineering projects, due to the existence of complex environmental conditions and multiple failure modes of certain performance functions, computational nonconvergence is easy to be occurred by using FORM. Compared to FORM, although the RSM can overcome the limitations in FORM when coping with relevant problems with multiple failure modes, the procedures of complex partial derivative solving, checking point seeking, and large numbers of iteration are still inevitable. Moreover, while MCS can provide high accuracy for the relevant application, it usually requires a large amount of calculation and high cost. Furthermore, when dealing with reliability analysis for the general pile foundation problem, adopting the HOMM based on onedimensional reduction integration and only considering the first three moments (i.e., mean, variance, and skewness) is an advantage of simplicity and high efficiency with a clear statistic concept. However, considering the great variability that existed in real engineering projects, the accuracy of yield reliability indexes is limited for engineering requirements when the absolute value of the skewness for the pile foundation is larger than 1 .

Therefore, based on the above assertions, in order to promote the accuracy of the predicted reliability assessment, this paper developed a HOMM based on two-dimensional reduction integration and take into account the first four moments (i.e., mean, variance, skewness, and kurtosis) to conduct the reliability assessment for bearing capacity of pile foundation. The remainder of this paper is organized as follows: In Section 2, the performance functions of bearing capacity for pile foundation are firstly established; in Section 3 , the expressions of afore-mentioned performance functions and the relevant reliability indexes determined by the HOMM based on two-dimensional reduction integration and cubic normal distribution are given. It is then followed by Section 4, an engineering example with four pile foundations with the different length-diameter ratio is analyzed by adopting above approach, which the probability distribution of performance function, reliability indexes, and quantile for those foundations are determined. In Section 5, a sensitivity analysis of the effect by relative soil layers on reliability indexes for the certain pile is discussed in detail. Eventually, the conclusions of this paper are presented in Section 6.

\section{Performance Function of the Bearing Capacity of Pile Foundation}

Assuming that the ultimate vertical bearing capacity of pile foundation is $\mathbf{R}$ and the total load applied on the pile top is $\mathbf{S}$, due to the existence of various uncertainties, $\mathbf{R}$ and $\mathbf{S}$ are a set of random vectors. According to the definition of reliability, when the pile foundation is in the failure state, the performance function of the bearing capacity of the pile foundation can be expressed as follows [21]:

$$
Z=G(\mathbf{R}, \mathbf{S})<0,
$$

where $\mathbf{R}$ generally depends on the bearing capacity of foundation soil to pile and $\mathbf{S}$ is the sum of the load $F_{k}$ transmitted by the superstructure to the top of pile foundation and the weight of the overlying soil $G_{k}$. Without the consideration of the eccentric effect, the failure function of the vertical bearing capacity of pile foundation can be written as follows:

$$
G(\mathbf{X})=\mathbf{R}-\left(F_{k}+G_{k}\right)<0 .
$$


2.1. Ultimate Vertical Bearing Capacity of Pile Foundation. Among many approximate estimation methods for the ultimate bearing capacity, the static load test is the most intuitive and reliable. However, the great dispersion of static load test datum and insufficient test samples bring to the results large error and high cost. Therefore, when studying the reliability of the vertical bearing capacity of pile foundation, $\mathbf{R}$ can be calculated according to the empirical parameter method in the code as follows [22, 23]:

$$
\mathbf{R}=R\left(\mathbf{q}_{\mathrm{si}}, q_{p}\right)=\pi \sum_{i=1}^{n} d_{i} q_{s i} \Delta l_{i}+q_{p} A_{p},
$$

where $q_{s 1}, \ldots, q_{s n}$ denote standard values of ultimate lateral resistance of pile foundation in the $i$-th layer, respectively. The symbol $q_{p}$ is used to denote standard values of ultimate tip resistance of pile foundation. $d_{i}$ is the diameter of the hole in the $i$-th layer, $\Delta l_{i}$ is the length of the pile in the $i$-th layer, and $A_{p}$ is the bottom area of the pile. Since the empirical parameter method is used to estimate $\mathbf{q}_{\mathrm{si}}$ and $q_{p}$, the random uncertainties of $\mathbf{q}_{\mathrm{si}}$ and $q_{p}$ are much greater than that of $d_{i}$, $\Delta l_{i}$, and $A_{p}$. In order to simplify the calculation and analysis, in this article, $\mathbf{q}_{\mathrm{si}}$ and $q_{p}$ are regarded as random variables and $d_{i}, \Delta l_{i}$, and $A_{p}$ are regarded as constants.

2.2. Total Loads Applied on the Tip of Pile. For general buildings subjected to low-level horizontal force, under the axial vertical force of the standard combination of load effect, vertical loads on the tip of the pile can be expressed as follows [22]:

$$
\mathbf{S}=\mathbf{S}\left(F_{k}, G_{k}\right)=F_{k}+G_{k}=S_{G}+S_{Q}+G_{k},
$$

where $F_{k}$ is the vertical force acting on the top surface of the bearing platform under the standard combination of load effects, which can be written as the sum of the vertical dead load effect $S_{G}$ and the vertical live load effect $S_{Q}$ on the tip of the pile. $G_{k}$ is the standard value of pile foundation cap and cap soil. And $F_{k}$ and $G_{k}$ can be approximated by the following equation $[23,24]$ :

$$
\mathbf{S}=\mathbf{S}\left(F_{k}, G_{k}\right)=F_{k}+G_{k} \approx n h A_{i} g_{i}+\gamma_{T} \mathcal{C}
$$

where $n$ is the number of floors; $h$ is the amplifying coefficient of axial pressure; $A_{i}$ is the loading area of vertical members on the $i$-th floor; $g_{i}$ is the representative value of gravity load converted to the unit building area of the $i$-th floor, 12 14 for frame structure, 14 16 for frame shear wall structure, and 15 18 for shear wall cylinder; $\gamma_{T}$ is the average weight of the bearing platform of the pile foundation and its overlying soil; and $c$ is the common volume of pile cap and its overlying soil. In this paper, $F_{k}$ and $G_{k}$ are only regarded as random variables.

\section{Pile Foundation Bearing Capacity Reliability Evaluation Based on HOMM}

Each moment of pile foundation bearing capacity performance function $G(\mathbf{X})$ can be expressed as follows [25-27]:

$$
\begin{aligned}
& \mu_{G}=E[G(\mathbf{X})]=\int_{\mathbf{X}} G(\mathbf{X}) f(\mathbf{X}) \mathrm{d} \mathbf{X}, \\
& \sigma_{G}^{2}=E\left\{\left[G(\mathbf{X})-\mu_{G}\right]^{2}\right\}=\int_{\mathbf{X}}\left[G(\mathbf{X})-\mu_{G}\right]^{2} f(\mathbf{X}) \mathrm{d} \mathbf{X}, \\
& \alpha_{k G} \sigma_{G}^{k}=E\left\{\left[G(\mathbf{X})-\mu_{G}\right]^{k}\right\}, \\
& =\int_{\mathbf{X}}\left[G(\mathbf{X})-\mu_{G}\right]^{k} f(\mathbf{X}) \mathrm{d} \mathbf{X}, \quad k>2,
\end{aligned}
$$

where $\mu_{G}$ and $\sigma_{G}$ are the mean and variance of $G(\mathbf{X})$, respectively; $\alpha_{k G}$ is the $k$-order central moment of $G(\mathbf{X})$, for instance, $\alpha_{3 G}$ is referred to as skewness coefficient of $G(\mathbf{X})$, which reflects symmetry or lack of symmetry of its distribution; $\alpha_{4 G}$ is known as kurtosis coefficient of $G(\mathbf{X})$, reflecting the sharpness or peakedness of its probability distribution; and $f(\mathbf{X})$ is the joint PDF of random variable $\mathbf{X}$.

3.1. The Two-Dimension-Reduction Integration of the Standard Normal Space. While $n$ denotes the number of random variables and $m$ denotes the $m$-point estimation of the standard normal space, $m^{n}$ points will be required for calculating equations (6) to (8). It needs a lot of computation when $n$ is large; therefore, for the sake of reducing the computation, the two dimension-reduction integration is introduced [28]; then, the $k$-th order original moments of performance function $G(\mathbf{X})$ can be approximated as follows:

$$
\begin{aligned}
\mu_{k G} & =E\left\{[G(\mathbf{X})]^{k}\right\}=E\left\{\left[G\left[T^{-1}(\mathbf{U})\right]\right]^{k}\right\} \\
& \cong \sum_{i<j} \mu_{i, j}^{k}-(n-2) \sum_{i=1}^{n} \mu_{i}^{k}+\frac{(n-1)(n-2)}{2} \mu_{0}^{k},
\end{aligned}
$$

where

$$
\begin{aligned}
\mu_{i, j}^{k} & =\int_{-\infty}^{+\infty} \int_{-\infty}^{+\infty}\left[G_{i j}\left[\mu_{1}, \ldots, T^{-1}\left(u_{i}\right), \ldots, T^{-1}\left(u_{j}\right), \ldots, \mu_{n}\right]\right]^{k} \phi\left(u_{i}\right) \phi\left(u_{j}\right) \mathrm{d} u_{i} \mathrm{~d} u_{j}, \\
\mu_{i}^{k} & =\int_{-\infty}^{+\infty}\left[G_{i}\left[\left(\mu_{1}, \ldots, T^{-1}\left(u_{i}\right), \ldots, \mu_{n}\right)\right]\right]^{k} \phi\left(u_{i}\right) \mathrm{d} u_{i} \\
\mu_{0}^{k} & =\left[G\left(\mu_{1}, \ldots, \mu_{i}, \ldots, \mu_{n}\right)\right]^{k}
\end{aligned}
$$


where $\mathbf{X}=\left(X_{1}, X_{2}, \ldots, X_{n}\right)^{T}$ is a vector of basis random variables of the system in original space and $\mathbf{U}=\left(U_{1}, U_{2}, \ldots\right.$, $\left.U_{n}\right)^{T}$ is a vector of basis random variables in standard normal space corresponding to $\mathbf{X} . i, j=1,2, \ldots, n$ and $i<j . \mu_{i}$ denotes the mean of the $i$-th random variables $X_{i}$, and $u_{i}$ denotes the estimation point of $i$-th random variables $U_{i}$ in standard normal space corresponding to $X_{i}$, and $T^{-1}$ is the inverse Rosenblatt transformation. Then, using the point estimate in standard normal space, the one-dimensional integral in equation (11) and two-dimensional integral in equation (10) can be approximated by the following equation:
TABLE 1: Five- and seven-point estimates corresponding to the estimating point and weight.

\begin{tabular}{lcc}
\hline & Estimation point & Weights \\
\hline Five-point & $u_{0}=0$ & $p_{0}=0.53333$ \\
estimate & $u_{1+}=-u_{1-}=1.35563$ & $p_{1+}=p_{1-}=0.22208$ \\
& $u_{2+}=-u_{2-}=2.85697$ & $p_{2+}=p_{2-}=1.12574 \times 10^{-2}$ \\
Seven-point & $u_{0}=0$ & $p_{0}=0.45714$ \\
estimate & $u_{1+}=-u_{1-}=1.15441$ & $p_{1+}=p_{1-}=0.24012$ \\
& $u_{2+}=-u_{2-}=2.36676$ & $p_{2+}=p_{2-}=0.03076$ \\
& $u_{3+}=-u_{3-}=3.75044$ & $p_{3+}=p_{3-}=5.4826910^{-4}$ \\
\hline
\end{tabular}

$$
\begin{gathered}
\mu_{i}^{k}=\sum_{r=1}^{m} P_{r}\left\{G_{i}\left[\left(\mu_{1}, \ldots, T^{-1}\left(u_{i, r}\right), \ldots, \mu_{n}\right)\right]\right\}^{k}, \\
\mu_{i, j}^{k}=\sum_{r_{1}=1}^{m} \sum_{r_{2}=1}^{m} P_{r 1} P_{r 2}\left\{G_{i j}\left[\mu_{1}, \ldots, T^{-1}\left(u_{i, r 1}\right), \ldots, T^{-1}\left(u_{i, r 2}\right), \ldots, \mu_{n}\right]\right\}^{k},
\end{gathered}
$$

where $u_{i, r}$ denotes the $r$-point estimation of the $i$-th random variable in the standard normal space and $P_{r}$ denotes its corresponding weight, which can be calculated as follows [29]:

$$
\begin{gathered}
u_{i, r}=\sqrt{2} x_{c}, \\
p_{r}=\frac{w_{c}}{\sqrt{\pi}}
\end{gathered}
$$

where $x_{c}$ and $w_{c}$ are the abscissas and weights for Hermite integration with the weight function exp $\left(-x^{2}\right)$ that can be found in Abramowitz and Stegun [29]. Specially, for a fiveand seven-point estimates in standard normal space, corresponding estimating point and weight is shown in Table 1.

After obtaining the $k$-order original moment estimate value $\mu_{k G}$ through equation (9), according to the relationship between the central moment and the origin moment [27], the mean, standard deviation, skewness, and kurtosis of $G$ (X) with $n$ random variables, respectively, can be obtained as follows:

$$
\begin{aligned}
\mu_{G} & =\mu_{1 G}, \\
\sigma_{G} & =\sqrt{\mu_{2 G}-\mu_{1 G}^{2}}, \\
{ }^{\prime} p t \alpha_{3 G} & =\frac{\left(\mu_{3 G}-3 \mu_{3 G} \mu_{1 G}+2 \mu_{1 G}^{2}\right)}{\sigma_{G}^{3}}, \\
\alpha_{4 G} & =\frac{\left(\mu_{4 G}-4 \mu_{3 G} \mu_{1 G}+6 \mu_{2 G} \mu_{1 G}^{2}-3 \mu_{1 G}^{4}\right)}{\sigma_{G}^{4}} .
\end{aligned}
$$

3.2. Description of Probability Distribution of $G(\boldsymbol{X})$ and Its Reliability Index. For the sake of simplicity and flexibility, Cai et al. [20] described the probability distribution of the performance function $G(\mathbf{X})$ for pile foundation bearing capacity by using the three-parameter lognormal distribution [30-33] and the third-moment reliability index $\beta_{3 \mathrm{M}}$, which is derived from this probability distribution. However, when the absolute value of skewness coefficient $\alpha_{3 G}$ is greater than 1, the approximated effect of the distribution of $G(\mathbf{X})$ does not work out so well. Under the circumstances, the cubic normal distribution, which its four parameters are the first four moments of performance function $G(\mathbf{X})$, will be introduced to improve approximated accuracy $[34,35]$. The PDF of the cubic normal distribution is formulated as follows:

$$
\begin{aligned}
X_{s} & =\frac{X-\mu_{G}}{\sigma_{G}}=-l_{1}+k_{1} U+l_{1} U^{2}+k_{2} U^{3}, \\
f\left(X_{s}\right) & =\frac{\phi(U)}{\sigma_{G}\left(k_{1}+2 l_{1} U+3 k_{2} U^{2}\right)},
\end{aligned}
$$

where $X_{s}$ is the standardized normal random variable, $f\left(X_{s}\right)$ is PDF of $G(\mathbf{X}), \phi(\cdot)$ is the PDF of the standard normal function, and the polynomial coefficients $l_{1}, k_{1}, l_{2}$, and $k_{2}$ are given as follows:

$$
\begin{aligned}
& l_{1}=\frac{\alpha_{3 G}}{6\left(1+6 l_{2}\right)} \\
& l_{2}=\frac{1}{36}\left(\sqrt{6 \alpha_{4 G}-8 \alpha_{3 G}^{2}-14}-2\right), \\
& k_{1}=\frac{1-3 l_{2}}{\left(1+l_{1}^{2}-l_{2}^{2}\right)}
\end{aligned}
$$




$$
k_{2}=\frac{l_{2}}{\left(1+l_{1}^{2}+12 l_{2}^{2}\right)} .
$$

Through the PDF obtained above, the fourth-moment reliability index $\beta_{4 M}$ and the corresponding failure probability $P_{f}$ of $G(\mathbf{X})$ can be expressed as follows:

$$
\begin{aligned}
\beta_{4 M} & =\frac{\sqrt[3]{2} p}{\sqrt[3]{-q_{0}+\Delta_{0}}}, \\
P_{f} & =\Phi\left(-\beta_{4 M}\right),
\end{aligned}
$$

where

$$
\begin{aligned}
\Delta_{0} & =\sqrt{q_{0}^{2}+4 p^{3}}, \\
p & =\frac{3 k_{1} k_{2}-l_{1}^{2}}{9 k_{2}^{2}}, \\
q_{0} & =\frac{2 l_{1}^{3}-9 k_{1} k_{2} l_{1}+27 k_{2}^{2}\left(-l_{1}+\beta_{2 M}\right)}{27 k_{2}^{2}} .
\end{aligned}
$$

And $\Phi(\cdot)$ is the cumulative density function (CDF) of the standard normal function; in order to make equation (21) operable, the following condition should be satisfied:

$$
\alpha_{4 G} \geq \frac{7+4 \alpha_{3 G}^{2}}{3} \text {. }
$$

To sum up, the reliability evaluation procedure of bearing capacity for pile foundation is able to be summarized as follows, and its flowchart is shown in Figure 1.

(1) To construct the performance function $G(\mathbf{X})$ of bearing capacity for pile foundation, the first four moments of $G(\mathbf{X})$ are obtained by point estimate based on two-dimension-reduction integration.

(2) When skewness coefficient $\left|\alpha_{3 G}\right| \leq 1$, the three-parameter lognormal distribution will be used to approximate probability distribution of $G(\mathbf{X})$; otherwise, for improving accuracy purpose, the probability distribution of $G(\mathbf{X})$ is approximated by the four-parameter cubic normal distribution.

(3) Reliability index, failure probability, and quantile will be determined according to this approximate probability distribution of $G(\mathbf{X})$.

\section{Engineering Application}

In this paper, the application of the above-mentioned approach is illustrated by a case from Cai et al. [20, 36]. In detail, a 7-storey reinforced concrete building adopting three types of punch filling piles with pile diameters $D$ of $800 \mathrm{~mm}$, $900 \mathrm{~mm}$ and $1,000 \mathrm{~mm}$ and pile length $L$ varied from $13-50 \mathrm{~m}$ is utilized for relevant analyzing. Specifically, the stratum relative to the pile foundation is mainly consisted of miscellaneous fill, gravel with cohesive soil, and strongly weathered granite. The relevant data of pile foundation in this project is graphically shown in Figure 2. For simplicity, in this paper, the piles in this case with four different lengthdiameter ratios (nos. 6, 9, 87, and 156 in Figure 3) are adopted for further analysis; the relevant parameters are described in Table 2.

For each pile, the mean value $\mu_{i}$, standard deviation $\sigma_{i}$, the coefficient of variance $(\mathrm{COV}) \delta_{I}$ of the ultimate shaft resistance $q_{s i}$, and ultimate tip resistance $q_{p}$ for the surrounding soil are determined by adopting the sample data provide from the report of in situ geological investigation in the following equations [27]:

$$
\begin{aligned}
& \mu_{i} \approx \widehat{\mu}_{i}=\frac{1}{n} \sum_{i=1}^{n} X_{i}, \\
& \sigma^{2} \approx \widehat{\sigma}^{2}=\frac{1}{n-1} \sum_{i=1}^{n}\left(X_{i}-\bar{X}\right)^{2}, \\
& \delta_{i} \approx \widehat{\delta}_{i}=\frac{\widehat{\sigma}}{\widehat{\mu}_{i}}
\end{aligned}
$$

where $\bar{X}$ denotes the mean of actual measured values of sample data, $X_{i}$ denotes the actual measured values of each sample of $i$-th, and $\widehat{\mu}, \widehat{\sigma}$ and $\widehat{\delta}$ are mean, variance, and COV of sample estimates value, respectively.

By observation of the statistical histogram obtained by the sample data, it is assumed the $f_{q s i}(X)$ is obeying the normal distribution and the $f_{q p}(X)$ is obeying the log-normal distribution; the result of $\mathrm{K}-\mathrm{S}$ test with a $5 \%$ degree of confidence showed that the test is failing to reject the null hypothesis. Therefore, in this paper, the ultimate shaft resistance $q_{s i}$ is considered to be obeying the normal distribution with $5 \%$ confidence, and ultimate tip resistance $q_{p}$ is considered to be obeying the lognormal distribution with 5\% confidence [37-39]. In addition, it is also assumed that the relevant random variables are independent, and the vertical force $F_{k}$ subjected to the pile caps and the mean value for the self-weight of pile caps and soils $G_{k}$ can be determined by equation (5). Specially, according to the national standard [40], the afore-mentioned vertical force $F_{k}$ and mean value for the self-weight $G_{k}$ approximately obey the lognormal distribution with both COV $\delta_{I}$ are 0.07 . The detailed values for each random variable and the corresponding probability distributions are illustrated in Table 3.

4.1. To Obtain the First Four Moments of Performance Function for Each Pile Foundation. According to Section 2, the performance function $G(\mathbf{X})$ for each pile foundation is able to be expressed as follows:

$$
G\left(\mathbf{q}_{s i}, \mathbf{q}_{p}, \mathbf{F}_{k i}, \mathbf{G}_{k}\right)=\pi \sum_{i=1}^{k} d_{i} q_{s i} \Delta l_{i}+q_{p} A_{p}-F_{k i}-G_{k} .
$$

In this paper, the commercial software Mathematic is utilized for relevant calculating. In detail, the first four moments of performance function $G(\mathbf{X})$ for relevant piles are obtained by adopting seven estimated points in standard normal space and Rosenblatt's inverse normal 


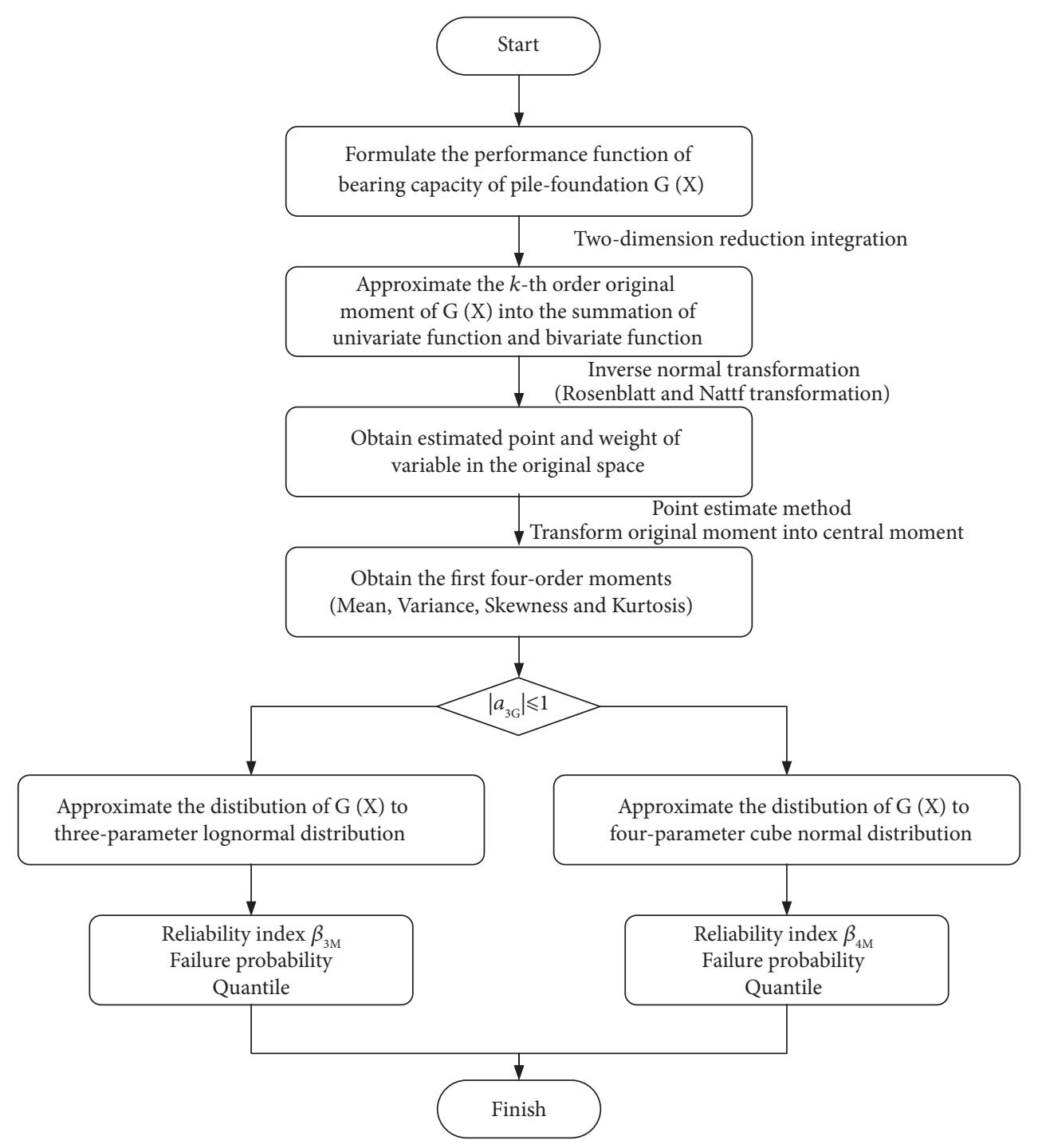

FIGURE 1: Flowchart of reliability evaluation procedure of bearing capacity for pile foundation based on HOMM.

transformation combined with equations (9) to (20), and the yield results are shown in Table 4 . Additionally, the relevant results $G(\mathbf{X})$ obtained by adopting MCS $10^{6}$ times are also presented in Table 4 for the purpose of comparison to verify the accuracy of the afore-mentioned approach.

It is shown that in Table 4, the results of the first four moments of performance function $G(\mathbf{X})$ for the pile foundation bearing capacity yielded by both HOMM and MCS exhibited a good consistency. However, the time required for the relevant calculation of HOMM is comparatively less than MCS, which reveals that this method can provide higher efficiency with reliable accuracy than MCS.

By conducting MCS with $10^{6}$ times for the performance function $G(\mathbf{X})$ of pile foundation bearing capacity, the calculated results of sample points are illustrated by quantile-quantile plot by commercial software SPSS in Figure 3. Specifically, in the quantile-quantile plot, the distribution function type is set as standard normal distribution; the vertical axis and the horizontal axis revealed the quantile of the performance function $G(\mathbf{X})$ of pile foundation bearing capacity and standard normal distribution, respectively. The bold and thin points are representing the results of sample data calculated of $G(\mathbf{X})$ and normal distribution corresponding to each quantile, respectively.

It is demonstrated that in Figure 3, both the bold and thin points are almost located in the same line, which revealed that the sample distribution of the performance function $G(\mathbf{X})$ and the standard normal distribution exhibit an obvious linear relationship. It is worth mentioned that in Table 4, it is found that the calculated result of the coefficient of skew coefficient $\alpha_{3 G} \approx 0$ and the Kurtosis coefficient $\alpha_{4 G} \approx 3$. Therefore, it is able to consider the bearing capacity of performance function $G(\mathbf{X})$ for each pile foundation is obeying normal distribution. 


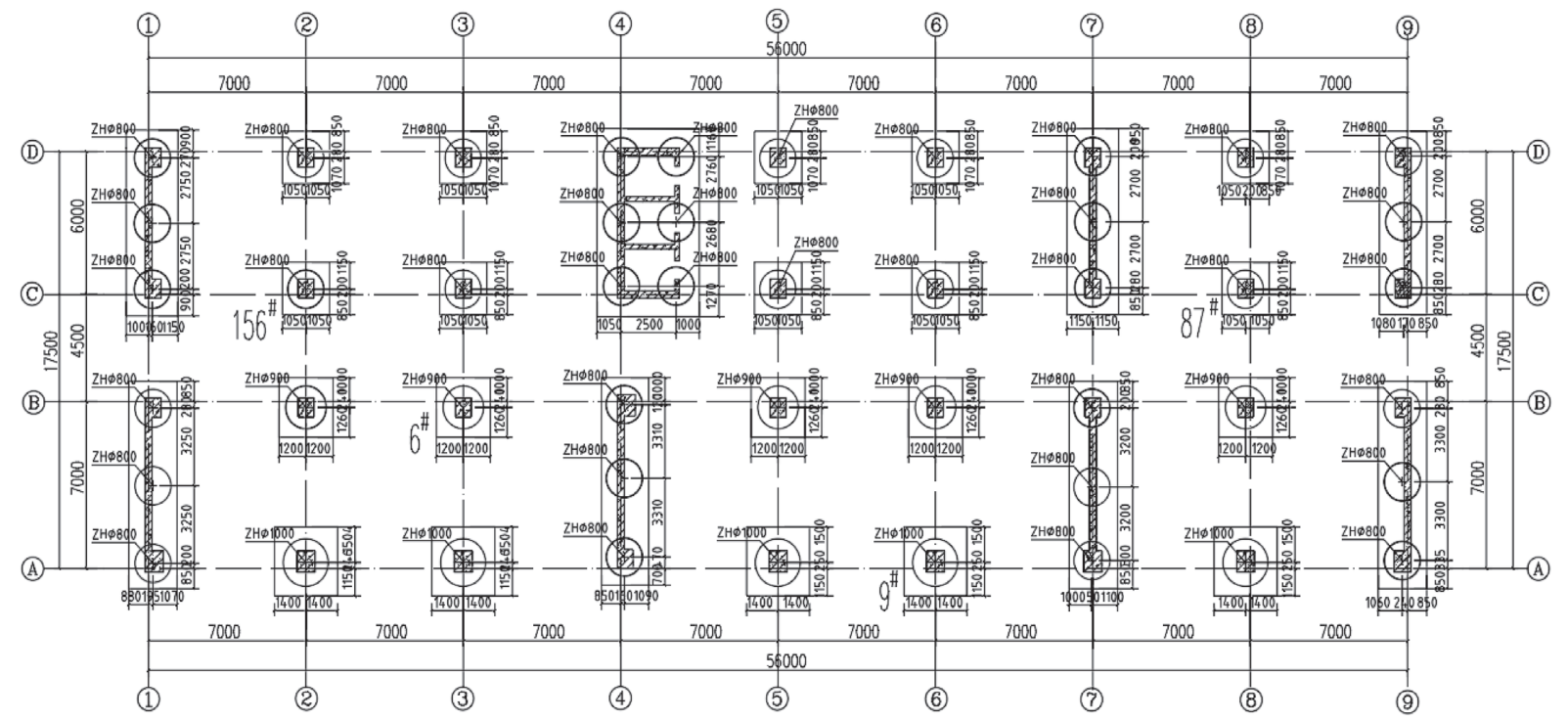

(a)

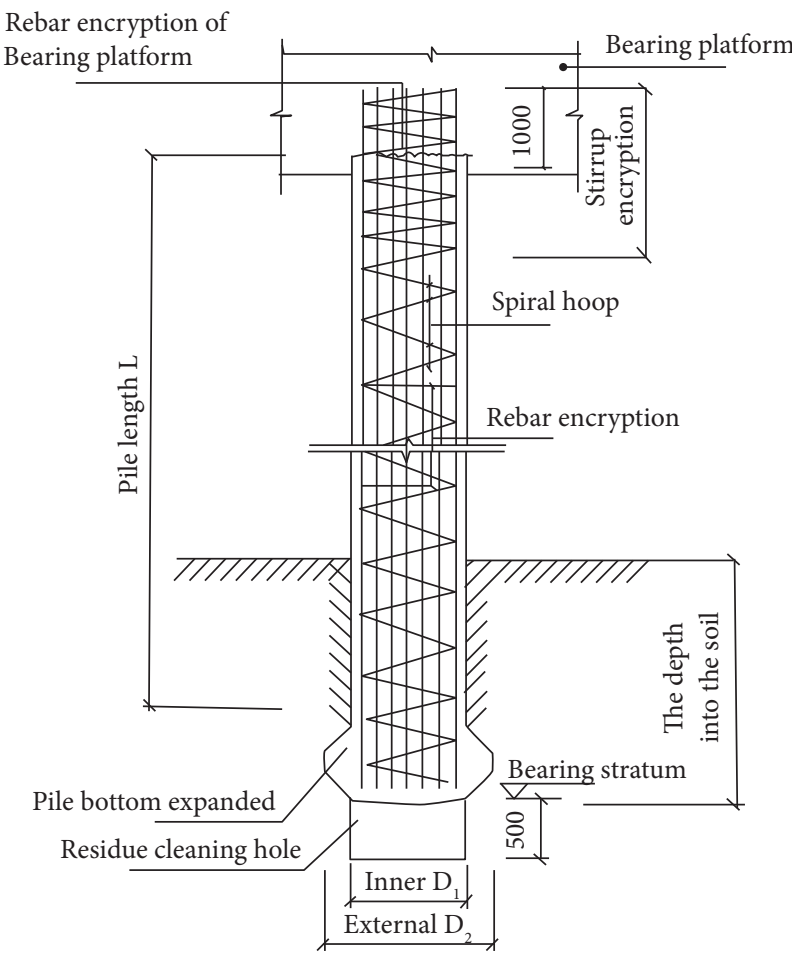

(b)

FIgURE 2: Continued. 


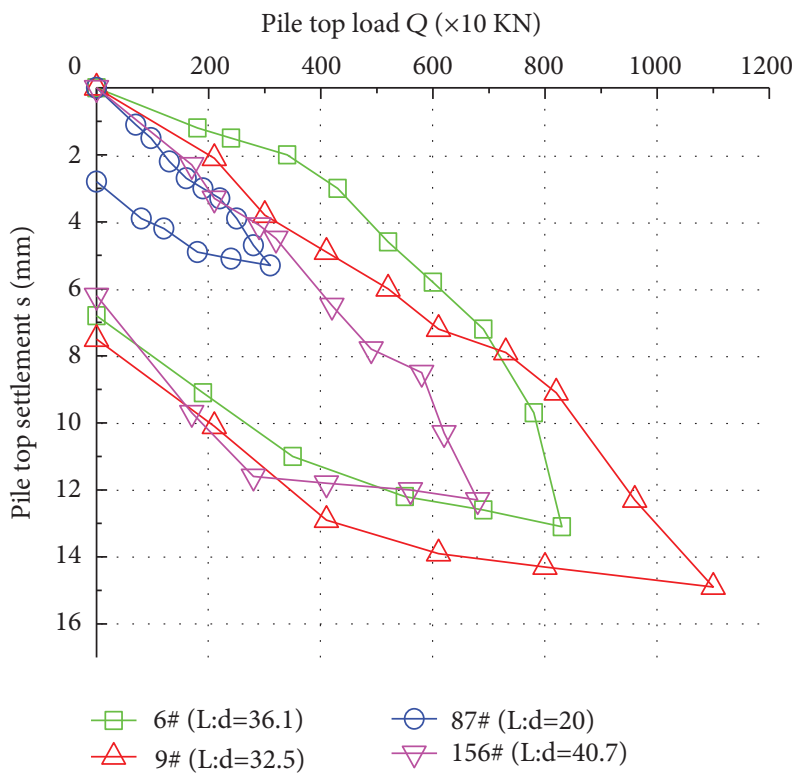

(c)

FIGURE 2: Diagrams of the relevant data of pile foundation in this project: (a) diagrams of pile foundation location layout of building, (b) detail diagrams of pile foundation, and (c) the Q-s curve of pile foundation for each pile foundation.

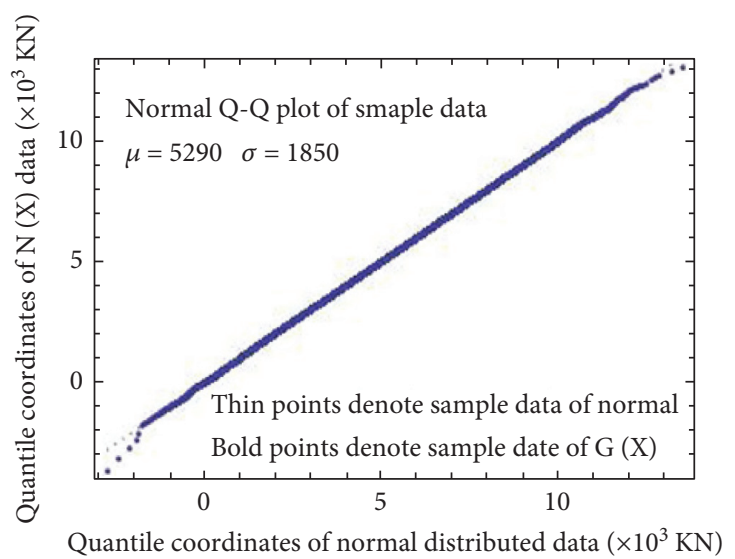

(a)

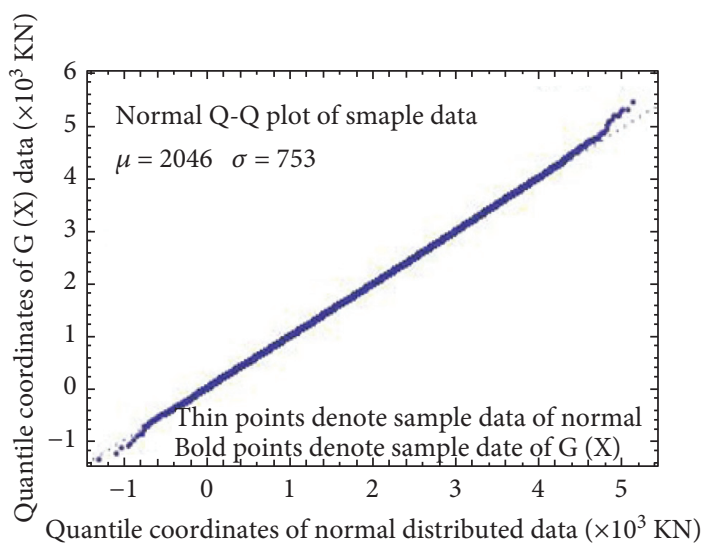

(c)

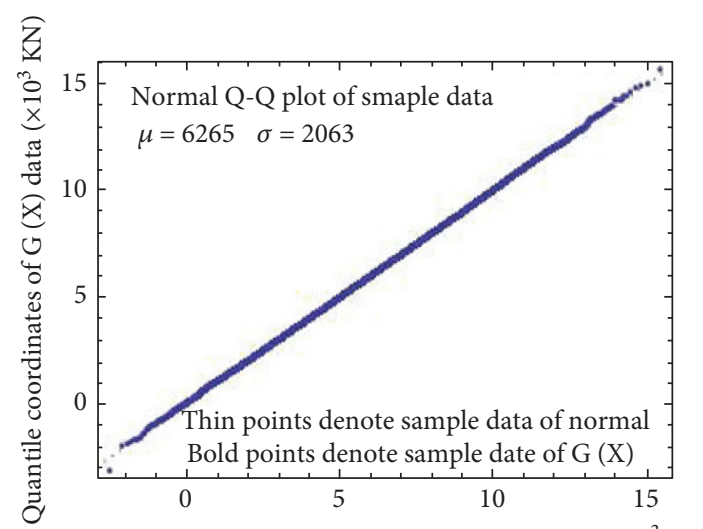

Quantile coordinates of normal distributed data $\left(\times 10^{3} \mathrm{KN}\right)$

(b)

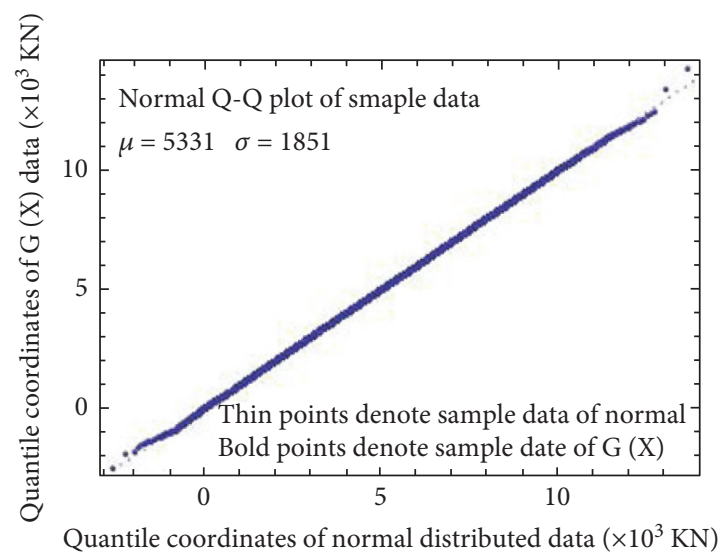

(d)

Figure 3: The normal $Q-Q$ plot of sample data of performance function $G(X)$ for each pile foundation: (a) the $Q-Q$ plot of sample data for the no. 6 pile, (b) the $Q-Q$ plot of sample data for the no. 6 pile, (c) the $Q-Q$ plot of sample data for the no. 87 pile, and (d) the $Q-Q$ plot of sample data for the no. 156 pile. 
TABle 2: Parameters of each pile foundation and soil layers.

\begin{tabular}{|c|c|c|c|c|c|c|}
\hline Pile no. & Length, $L(\mathrm{~m})$ & Elastic modulus, $E(\mathrm{MPa})$ & Diameter, $D(\mathrm{~mm})$ & Soil layer & Altitude (m) & Thickness (m) \\
\hline \multirow{4}{*}{$6^{\#}$} & & & & Miscellaneous fill & $41 \sim 50$ & 9 \\
\hline & 32.54 & 31.5 & 900 & Clayey gravel & $20 \sim 41$ & 21 \\
\hline & & & & Intensely weathered granite & $0 \sim 20$ & 20 \\
\hline & & & & Miscellaneous fill & $43 \sim 50$ & 7 \\
\hline \multirow[t]{3}{*}{$9^{\#}$} & 32.50 & 31.5 & 1,000 & Clayey gravel & $33 \sim 43$ & 10 \\
\hline & & & & Intensely weathered granite & $0 \sim 33$ & 33 \\
\hline & & & & Miscellaneous fill & $44 \sim 50$ & 6 \\
\hline \multirow[t]{3}{*}{$87^{\#}$} & 16 & 31.5 & 800 & Clayey gravel & $35 \sim 44$ & 9 \\
\hline & & & & Intensely weathered granite & $0 \sim 35$ & 35 \\
\hline & & & & Miscellaneous fill & $47 \sim 50$ & 3 \\
\hline \multirow[t]{2}{*}{$156^{\#}$} & 32.58 & 31.5 & 800 & Clayey gravel & $34 \sim 47$ & 13 \\
\hline & & & & Intensely weathered granite & $0 \sim 34$ & 34 \\
\hline
\end{tabular}

TABle 3: Probability model and statistical parameters of basic random variables.

\begin{tabular}{|c|c|c|c|}
\hline Random variance & Probability distribution & Mean & $\operatorname{COV}(\%)$ \\
\hline Ultimate lateral resistance of miscellaneous fill, $q_{s 1}$ & Normal & $22(\mathrm{kPa})$ & 30 \\
\hline Ultimate lateral resistance of gravel with cohesive soil, $q_{s 2}$ & Normal & $100(\mathrm{kPa})$ & 30 \\
\hline Ultimate lateral resistance of strongly-weathered granite, $q_{s 3}$ & Normal & $120(\mathrm{kPa})$ & 30 \\
\hline Ultimate tip resistance of strongly-weathered granite, $q_{p}$ & Lognormal & $1,800(\mathrm{kPa})$ & 30 \\
\hline Vertical loads on tip of the pile of no. $6, F_{k 6}$ & Lognormal & $3,200(\mathrm{kN})$ & 7 \\
\hline Vertical loads on tip of the pile of no. $9, F_{k 9}$ & Lognormal & $4,600(\mathrm{kN})$ & 7 \\
\hline Vertical loads on tip of the pile of no. $87, F_{k 87}$ & Lognormal & $1,750(\mathrm{kN})$ & 7 \\
\hline Vertical loads on tip of the pile of no. $156, F_{k 156}$ & Lognormal & $4,000(\mathrm{kN})$ & 7 \\
\hline Weight of bearing platform and soil, $G_{k}$ & Lognormal & $30(\mathrm{kN})$ & 2 \\
\hline
\end{tabular}

TABLE 4: Calculating comparison between HOMM and MCS.

\begin{tabular}{lcccccc}
\hline \multirow{2}{*}{ Calculation method } & \multirow{2}{*}{ Pile no. } & \multicolumn{3}{c}{ The first four moments of $G(X)$} & $\alpha_{4 G}$ & Elapsed time, $t$ (second) \\
& & $\mu_{G}(\mathrm{kN})$ & $\sigma_{G}(\mathrm{kN})$ & $\alpha_{3 G}$ & 27.33 \\
\multirow{3}{*}{ MCS } & $6^{\#}$ & $5.30 \times 10^{3}$ & $1.87 \times 10^{3}$ & $5.69 \times 10^{-3}$ & 3.00 & 26.51 \\
& $9^{\#}$ & $6.23 \times 10^{3}$ & $2.10 \times 10^{3}$ & $6.72 \times 10^{-3}$ & 3.00 & 20.67 \\
& $87^{\#}$ & $2.04 \times 10^{3}$ & $7.57 \times 10^{2}$ & $4.26 \times 10^{-2}$ & 3.02 & 22.57 \\
HOMM & $156^{\#}$ & $5.33 \times 10^{3}$ & $1.89 \times 10^{3}$ & $4.35 \times 10^{-3}$ & 3.00 & 0.056 \\
& $6^{\#}$ & $5.31 \times 10^{3}$ & $1.87 \times 10^{3}$ & $5.69 \times 10^{-3}$ & 3.00 & 0.075 \\
& $9^{\#}$ & $6.23 \times 10^{3}$ & $2.10 \times 10^{3}$ & $7.72 \times 10^{-3}$ & 3.00 & 0.050 \\
& $87^{\#}$ & $2.05 \times 10^{3}$ & $7.57 \times 10^{2}$ & $4.27 \times 10^{-2}$ & 3.00 & 0.069 \\
\hline
\end{tabular}

4.2. To Calculate the Reliability Index of Performance Function $G(X)$ for Each Pile Foundation. The results of the fourthmoment reliability index $\beta_{4 \mathrm{M}}$ and the corresponding failure probability $P_{f}$ based on the approximated probability distribution of $G(\mathbf{X})$ of bearing capacity for each pile foundation are listed in Table 5, which can be obtained by substituting the results of Table 4 into equations (27) to (32). The relevant results yield by adopting FORM and MCS of $10^{6}$ times are also listed in Table 5 for comparison purposes.

It is found that in Table 5, the calculation of the fourthmoment reliability index $\beta_{4 \mathrm{M}}$ and the corresponding failure probability $P_{f}$ based on HOMM required less time than MCS and possessed clearer statistical concept without the requirement of iteration and solving partial derivative equations. In addition, the results obtained by the HOMM and that yield from the three-parameters lognormal distribution proposed by literature [20] are emerged in high agreement, which revealed that the accuracy of the HOMM is reliable. Moreover, it is also observed that the calculated fourthmoment reliability index $\beta_{4 M}$ for the four different pile foundations is larger than the valued $\left(\beta_{T} \geq 2.7\right)$ of tertiary ductility failure members listed in "unified standard for reliability design of building structures" [21], which is also in consistence of the conclusions with the literature [36]. Therefore, it is reasonable to be concluded that the HOMM is providing an effective path for the reliability of the bearing capacity of pile foundation in the engineering field.

4.3. Probability Distribution of Bearing Capacity of Performance Function $G(X)$ for Each Pile Foundation. The results in Table 4 are substituted into equations (21) to (26) to obtain the PDF curve of performance function $G(\mathbf{X})$ of bearing capacity for each pile foundation as shown in 
TABLE 5: The reliability index and failure probability result of three methods.

\begin{tabular}{lccccc}
\hline \multirow{2}{*}{ Pile no } & \multicolumn{2}{c}{ FORM } & \multicolumn{2}{c}{ MCS } & \multicolumn{2}{c}{ HOMM } & $P_{f}$ \\
& $P_{f}$ & $\beta_{\text {FORM }}$ & $P_{f}$ & $\beta_{\text {MCS }}$ & $2.11 \times 10^{-3}$ \\
$6^{\#}$ & $2.21 \times 10^{-3}$ & 2.85 & $2.17 \times 10^{-3}$ & 2.85 & 2.85 \\
$9^{\#}$ & $1.23 \times 10^{-3}$ & 3.03 & $1.17 \times 10^{-3}$ & 3.04 & $1.12 \times 10^{-3}$ \\
$87^{\#}$ & $3.27 \times 10^{-3}$ & 2.72 & $2.99 \times 10^{-3}$ & 2.75 & $2.90 \times 10^{-3}$ \\
$156^{\#}$ & $1.89 \times 10^{-3}$ & 2.90 & $1.86 \times 10^{-3}$ & 2.90 & $1.81 \times 10^{-3}$ \\
Elapsed time (second) & \multicolumn{2}{c}{0.164} & & 2.76 & 2.91 \\
\hline
\end{tabular}

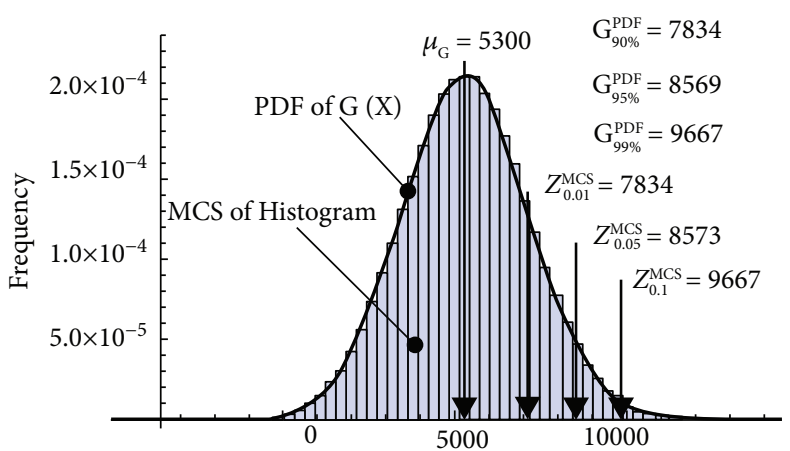

The results of performance function $\mathrm{G}(\mathrm{X})(\mathrm{KN})$

(a)

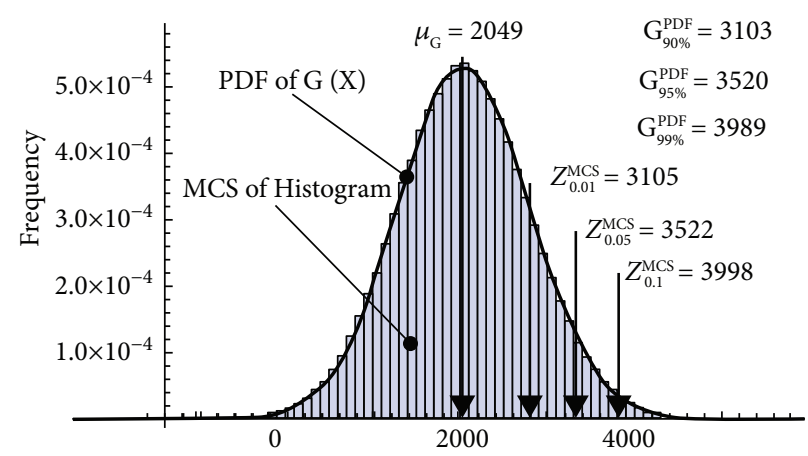

The results of performance function $\mathrm{G}(\mathrm{X})(\mathrm{KN})$

(c)

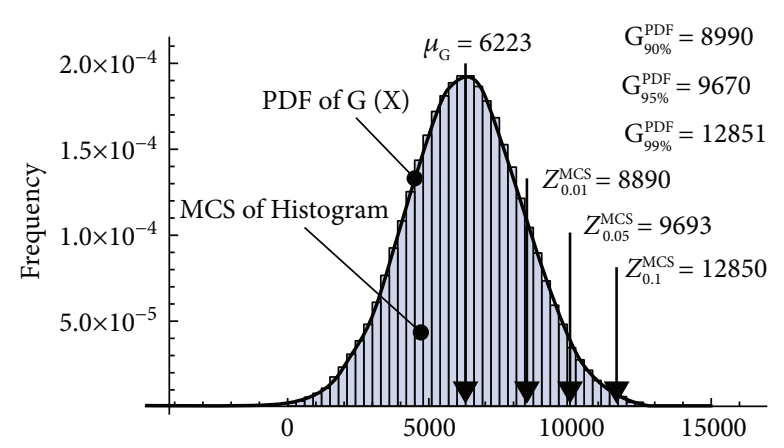

The results of performance function $\mathrm{G}(\mathrm{X})(\mathrm{KN})$

(b)

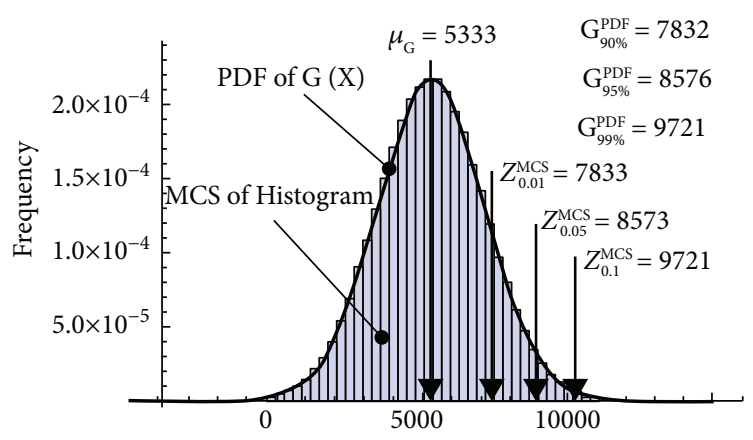

The results of performance function $\mathrm{G}(\mathrm{X})(\mathrm{KN})$

(d)

FIGURE 4: Histogram and PDF curve of a performance function for each pile foundation: (a) histogram and PDF curve for $G(X)$ of no. 6, (b) histogram and PDF curve for $G(X)$ of no. 9, (c) histogram and PDF curve for $G(X)$ of no. 87, and (d) histogram and PDF curve for $G(X)$ of no. 156.

Figure 4. For comparison, Figure 4 also shows the frequency histogram of $10^{6} \mathrm{MCS}$.

Figure 4 shows that the outer contour of the frequency histogram of $G(\mathbf{X})$ is close to the PDF curve of $G(\mathbf{X})$ obtained by equations (21) to (26). For each pile, MCS is used to calculate the quantiles with confidence levels of $90 \%$, $95 \%$, and $99 \%$, (i.e., $z_{0.01}^{\mathrm{MCS}}, z_{0.05}^{\mathrm{MCS}}$ and $z_{0.1}^{\mathrm{MCS}}$ ), and those results have a great agreement with the values of $G_{90 \%}^{\mathrm{PDF}}, G_{95 \%}^{\mathrm{PDF}}$ and $G_{99 \%}^{\mathrm{PDF}}$, which calculated from the PDF curve obtained by equations (21) to (26). Meanwhile, the probability function curve of $G(\mathbf{X})$ from the three-parameter lognormal distribution proposed by literature [20] is the same as the probability function curve proposed in this paper; that is to say, both of candidate approximated probability distribution is able to be reliable used in conventional pile foundation in engineering. In other words, Figure 4 also illustrates that the PDF of the probability distribution of the performance function $G(\mathbf{X})$ of bearing capacity for pile foundation in conventional engineering can be described by equations (21) to (26), which provides a reference for the design and bearing capacity analysis of pile foundation in practice.

\section{Sensitivity Analysis on Bearing Capacity Reliability in Pile Foundations}

In engineering practice, general differences exist between the measured and statistical values of geotechnical parameters. In the aforementioned example, the static loading test can only reflect the interaction between four sampled piles and 


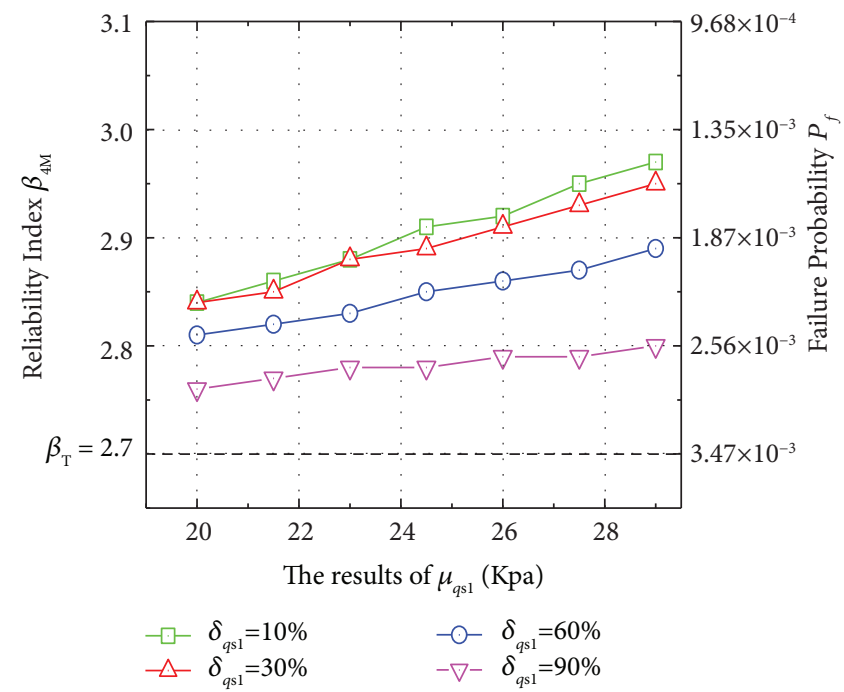

(a)

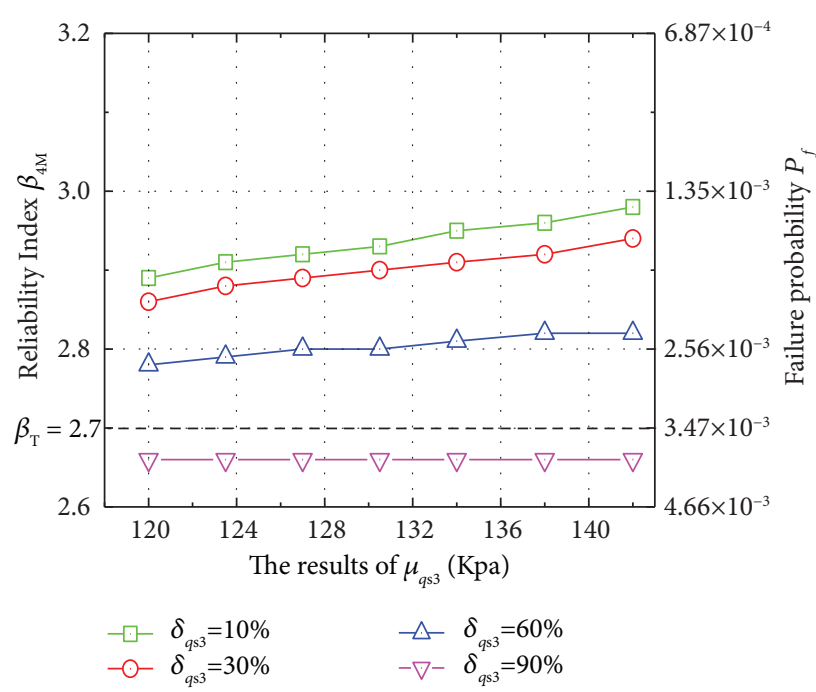

(c)

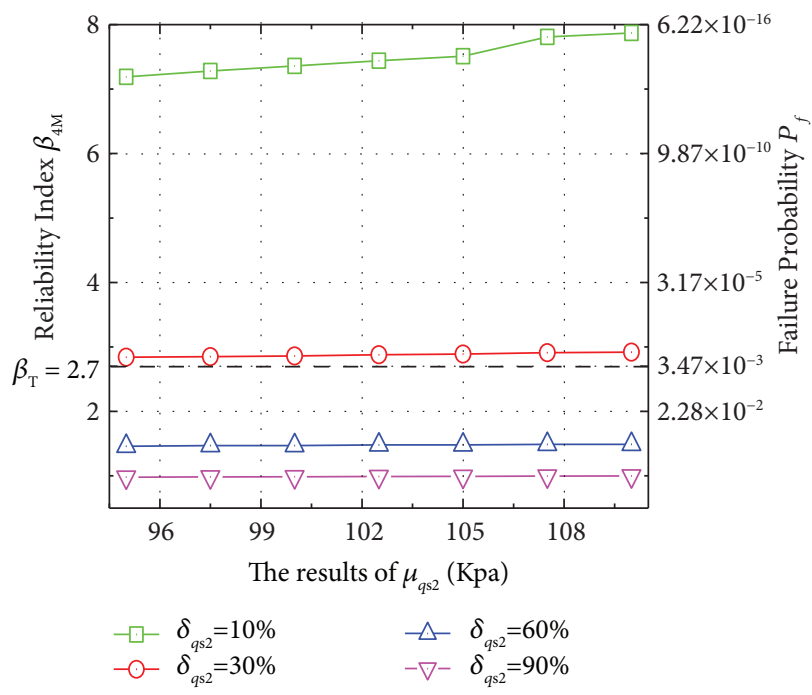

(b)

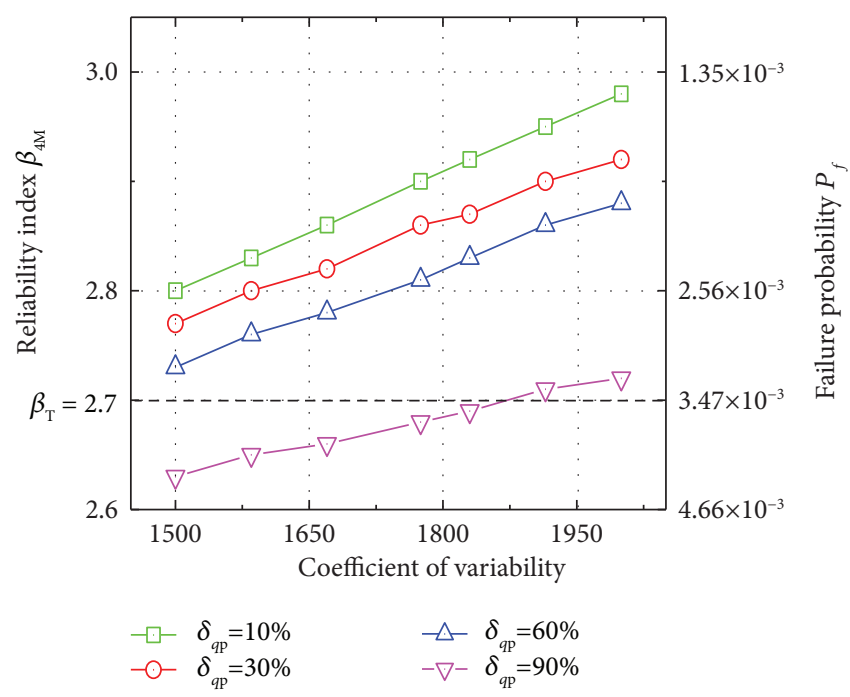

(d)

FIGURE 5: Sensitivity analysis for relative soil layer of no.6 pile foundation: (a) relationship between mean $\mu_{q s 1}$ and reliability index $\beta_{4 M}$, (b) relationship between mean $\mu_{q s 2}$ and reliability index $\beta_{4 M}$, (c) relationship between mean $\mu_{q s 3}$ and reliability index $\beta_{4 M}$, and (d) relationship between COV and reliability index $\beta_{4 M}$.

each soil layer, respectively. However, the values of parameters in other soil layers can hardly be precise enough to the actual ones. Therefore, it is necessary to study the influence of the uncertainty of soil parameters on the reliabilities of pile foundations.

Taking 6\# pile as an example, based on the HOMM, the effects of different mean values and variation coefficients of ultimate pile side resistance and ultimate pile end resistance on the reliability of bearing capacity for pile foundation are studied. The results are shown in Figure 5.

Figure 4(a) shows that the larger $\mu_{q s 1}$ is, the better the fourth-moment reliability index $\beta_{4 \mathrm{M}}$ of the pile foundation is. But with the incensement of $\delta_{q s 1}$, the impact of $\mu_{q s 1}$ on $\beta$ will decrease gradually. Additionally, the effect of $\delta_{q s 1}$ on $\beta$ will dramatically increase, if $\delta_{q s 1}>30 \%$.

Figure 4(b) shows that $\mu_{q s 2}$ has little effect on the reliability of pile foundation. What's more, the larger $\delta_{q s 2}$ is, the more unfavorable it is to the reliability of pile foundation. When $\delta_{q s 2}$ is less than $30 \%$, the influence of $\delta_{q s 2}$ on $\beta_{4 \mathrm{M}}$ is particularly obvious, which implies that $\delta_{q s 2}$ is a sensitive factor of 6\# pile. When $\delta_{q s 2}$ is larger, the influence of $\delta_{q s 2}$ on reliability results starts to decrease. When $\delta_{q s 2}$ is greater than $30 \%, \beta_{4 \mathrm{M}}$ is lower than $\beta_{T}$ of grade III ductile members; the pile foundation tends to be unsafe. 
Figure $4(\mathrm{c})$ shows that the larger $\mu_{q s 3}$ is, the more favorable it is to the reliability of pile foundation. However, with the increase of $\delta_{q s 3}$, its influence on $\beta_{4 \mathrm{M}}$ gradually decreases. When $\delta_{q s 2}$ exceeds $83 \%, \beta_{4 \mathrm{M}}$ is lower than $\beta_{T}$; the pile foundation tends to be unsafe.

Figure $4(\mathrm{~d})$ shows that the larger $\mu_{q p}$ is, the better the reliability of pile foundation is. Simultaneously, the larger the $\delta_{q s 2}$ is, the more unfavorable it is to the reliability of pile foundation. When $\delta_{q s 2}$ exceeds $62 \%, \beta_{4 \mathrm{M}}$ begins to appear lower than $\beta_{T}$; the pile foundation tends to be unsafe.

In conclusion, for $6 \#$ pile, the variation coefficient of ultimate resistance $\left(q_{s i}\right.$ and $q_{p}$ ) of each soil layer has a more obvious impact on the fourth-moment reliability index $\beta_{4 \mathrm{M}}$ than the mean value, and the greater $\delta_{q s i}$ is, the more unfavorable it is to the reliability of pile foundation. The coefficient of variation of the second layer of soil is the sensitivity factor of $6 \#$ pile.

Therefore, ensuring the accuracy of soil layer parameters in the project is conducive to accurately and reasonably predicting the reliability of pile foundation. The results of the uncertainty analysis of the parameters of each soil layer of the pile foundation are able to be used as a theoretical reference for engineers in pile foundation design and construction.

\section{Conclusions}

In this paper, the reliability assessment of the performance function for pile foundation based on the HOMM was conducted. Specifically, by analyzing four pile foundations with different ratios of length to diameter, the first four moments of performance function $G(\mathbf{X})$ for pile foundation were initially determined by adopting the point estimate based on two dimensions reduction integration. After that, the probability distribution function of the performance function $G(\mathbf{X})$ was obtained by utilizing the approximate cubic normal distribution based on the first four moments, and then the fourth-moment reliability index $\beta_{4 M}$ of the bearing capacity for the pile foundation was further estimated. Finally, in order to investigate the impact on the reliability of the bearing capacity for pile foundation caused by the variability of different soil layers, this paper also conducted a reliability sensitivity analysis on the certain pile by applying the HOMM. The conclusions can be drawn up as follows:

(1) Compared to the predicted results of the reliability index by adopting MCS, the results yielded by the HOMM show a good consistency. However, the HOMM was shown a higher efficiency.

(2) Compared to the FORM, using HOMM to calculate the reliability index of the bearing capacity for the pile foundation was not required to the solving procedures of partial derivatives, checking point tracing, and iteration, which the simplicity and efficiency of the HOMM are verified.

(3) The predicted results of the reliability index for the bearing capacity of the four different pile foundations were greater than the grade III ductile members values of the target reliability index provided in the national code, which revealed the safety of those pile foundations were guaranteed.

(4) It was suggested that the probability distribution function of the bearing capacity for pile foundation could be approximated by three-parameter lognormal distribution when the skewness $\left|\alpha_{3 G}\right| \leq 1$. Otherwise, the four-parameter cubic normal distribution was recommended.

(5) Compared to the mean of the ultimate resistance of relevant soil layers, the results of the sensitivity analysis showed that the COV emerge higher sensitivity; in detail, the reliability index exhibited a decrease trend as the COV increased; additionally, the sensitivity factor for the certain pile was found as the $\mathrm{COV}$ of the soil on the second layer.

\section{Data Availability}

The data used to support the findings of this study are available from the corresponding author upon request.

\section{Conflicts of Interest}

The authors declare that there are no conflicts of interest.

\section{Authors' Contributions}

Qiang Fu and Xiao Li conceived, designed, and performed the study. And Xueji Cai collected statistical sample dates of engineering examples used in the paper. Zilong Meng, Yinuo Liu, and Huawei Fu wrote and revised the paper together. The authors have read and approved the final published manuscript.

\section{Acknowledgments}

This work was supported by the National Natural Science Foundation of China, grant numbers U1134209 and U1434204, and Education and Science Research Program for Fujian Middle Aged and Young Teachers, grant number JT180504.

\section{References}

[1] H. G. Poulos and E. H. Davis, Pile Foundation Analysis and Design, Wiley, Hoboken, NJ, USA, 1981.

[2] T. Yang, A. P. S. Selvadurai, and S. H. Wang, "The influence of seepage characteristics on the reliability of a tunnel roof under dynamic disturbances," Geomechanics and geophysics for geoenergy and geo-resources, vol. 7, no. 92, pp. 1-12, 2021.

[3] L. L. Li, Z. Y. Liu, J. W. Jin, and J. F. Xue, "A modified method for the prediction of Monte Carlo simulation based on the similarity of random field instances," Geomechanics and geophysics for geo-energy and geo-resources, vol. 7, no. 37, pp. 1-12, 2021.

[4] L. Gu, Z. Wang, Q. Huang, G. Ye, and F. Zhang, "Numerical investigation into ground treatment to mitigate the permanent train-induced deformation of pile-raft-soft soil system," Transportation geotechnics, vol. 24, Article ID 100368, 2020. 
[5] D. H. Wu and C. S. Johnson, "Radiation-damping effects on relaxation-time measurements by the inversion-recovery $\mathrm{m}$," Journal of Magnetic Resonance, vol. 110, no. 1, pp. 113-117, 1994.

[6] K. O. Ronold and P. Bjerager, "Model uncertainty representation in geotechnical reliability analyses," International Journal of Rock Mechanics and Mining Science \& Geomechanics Abstracts, vol. 29, no. 5, p. 316, 1992.

[7] V. Tandjiria, C. I. Teh, and B. K. Low, "Reliability analysis of laterally loaded piles using response surface methods," Structural Safety, vol. 22, no. 4, pp. 335-355, 2000.

[8] M. H. Zhao, Z. Z. Yu, and S. Y. Hua, "Improved response surface method and its application to Reliability analysis of piles under inclined loads," Rock and Soil Mechanics, vol. 28, no. 12, pp. 2539-2542, 2007, in Chinese.

[9] D. Q. Li and Y. L. Li, "Reliability evaluation of bored pile considering possibility of toe debris presence," Rock and Soil Mechanics, vol. 1, no. 29, pp. 155-160, 2008, in Chinese.

[10] D. Q. Li, "Evaluation of statistical dependency for reliability analysis of single pile," Rock and Soil Mechanics, vol. 2, no. 03, pp. 633-638, 2008, in Chinese.

[11] C. L. Chan and B. K. Low, "Reliability analysis of laterally loaded piles involving nonlinear soil and pile behavior," Journal of Geotechnical and Geoenvironmental Engineering, vol. 135, no. 3, pp. 431-443, 2009.

[12] G. L. S. Babu and B. M. Basha, "Optimum design of cantilever sheet pile walls in sandy soils using inverse reliability approach," Computers and Geotechnics, vol. 35, no. 2, pp. 134-143, 2008.

[13] B. M. Basha and G. L. S. Babu, "Target reliability based design optimization of anchored cantilever sheet pile walls," Canadian Geotechnical Journal, vol. 45, no. 4, pp. 535-548, 2008.

[14] K. Kwak, K. J. Kim, J. Huh, J. H. Lee, and J. H. Park, "Reliability-based calibration of resistance factors for static bearing capacity of driven steel pipe piles," Canadian Geotechnical Journal, vol. 47, no. 5, pp. 528-538, 2010.

[15] A. Teixeira, Y. Honjo, A. G. Correia, and A. A. Henriques, "Sensitivity analysis of vertically loaded pile reliability," Soils and Foundations, vol. 52, no. 6, pp. 1118-1129, 2012.

[16] G. L. Yoon, S. B. Kim, and J. H. Yi, "Reliability analysis of pile foundation for an offshore wind turbine," Japanese geotechnical society special publication, vol. 2, no. 71, pp. 2456-2460, 2016.

[17] M. Kawa, I. Bagińska, and M. Wyjadłowski, "Reliability analysis of sheet pile wall in spatially variable soil including CPTu test results," Archives of civil and mechanical engineering, vol. 19, no. 2, pp. 598-613, 2019.

[18] D. Chanda, R. Saha, and S. Haldar, "Influence of inherent soil variability on seismic response of structure supported on pile foundation," Arabian Journal for Science and Engineering, vol. 44, no. 2, pp. 5009-5025, 2019.

[19] Z. J. Xu, X. Han, J. J. Zheng, and F. Yuan, "Study on reliability optimization design method of piles under vertical loads," J. Huazhong univ. of sci. and tech. (Natural science edition), vol. 48, no. 5, 2020, in Chinese.

[20] X. J. Cai, Q. Fu, J. T. Li, X. Li, Z. L. Meng, and S. Z. Li, "Study on reliability of bearing capacity of single pile based on higher order moment method," Journal of Nanchang institute of technology, vol. 40, no. 3, pp. 25-32, 2021, in Chinese.

[21] China Academy of Building Research, GB 50068-2018 Unified Standard for Reliability Design of Building Structures, China architecture and building press, Beijing, China, 2018, in Chinese.
[22] China academy of Building Research, JGJ 94-2008 Technical Code for Building Pile Foundations, China Architecture and building press, Beijing, China, 2008, in Chinese.

[23] M. H. Zhao, Soil Mechanics and Foundation Engineering, Wuhan university technology, press, Wuhan,, 2000, in Chinese.

[24] Q. Zhang, Y. G. Zhao, K. Kolozvari, and L. Xu, "Simplified model for assessing progressive collapse resistance of reinforced concrete frames under an interior column loss," Engineering Structures, vol. 215, no. 15, 15 pages, 2020.

[25] Y. G. Zhao and T. Ono, "Moment methods for structural reliability," Structural Safety, vol. 23, no. 1, pp. 47-75, 2001.

[26] Y.-G. Zhao and T. Ono, "New point estimates for probability moments," Journal of Engineering Mechanics, vol. 126, no. 4, pp. 433-436, 2000.

[27] Y. G. Zhao and Z. H. Lu, Approaches from Perspectives of Statistical Moments, Wiley, Hoboken, NJ, USA, 2021.

[28] S. Rahman and $\mathrm{H} . \mathrm{Xu}$, "A univariate dimension-reduction method for multi-dimensional integration in stochastic mechanics," Probabilistic Engineering Mechanics, vol. 19, no. 4, pp. 393-408, 2004.

[29] I. E. Abramowitz and M. Stegun, Handbook of Mathematical Functions, Dover publications, Mineloa, NY, USA, 1972.

[30] Y.-G. Zhao, Z.-H. Lu, and T. Ono, "A Simple third-moment method for structural reliability," Journal of Asian Architecture and Building Engineering, vol. 5, no. 1, pp. 129-136, 2006.

[31] Y.-G. Zhao, T. Ono, H. Idota, and T. Hirano, "A Three-parameter distribution used for structural reliability evaluation," Journal of Structural and Construction Engineering (Transactions of AIJ), vol. 66, no. 546, pp. 31-38, 2001.

[32] Y. G. Zhao, Z. H. Lu, and T. Ono, "First three moments of some commonly used performance functions," Journal of structural \& construction engineering, vol. 72, no. 617, pp. 31-37, 2017.

[33] Y.-G. Zhao and T. Ono, "Third-moment standardization for structural reliability analysis," Journal of Structural Engineering, vol. 126, no. 6, pp. 724-732, 2000.

[34] Y.-G. Zhao and Z.-H. Lu, "Applicable range of the fourthmoment method for structural reliability," Journal of Asian Architecture and Building Engineering, vol. 6, no. 1, pp. 151158, 2007.

[35] Y.-G. Zhao and Z.-H. Lu, "Cubic normal distribution and its significance in structural reliability," Structural Engineering \& Mechanics, vol. 28, no. 3, pp. 263-280, 2008.

[36] X. J. Cai, L. Yan, L. Huang, and Y. Shen, "An analysis of influence of length-diameter ratio of pile on bearing capacity of single pile in building," Journal of wuyi univeristy, vol. 38, no. 9, pp. 67-71, 2019, in Chinese.

[37] Q. Zhang, P. Y. Lun, and X. Li, "A simplified approach for prediction of concrete resistivity: experimental study and mathematic model," Materials and Structures, vol. 54, no. 4, p. 155, 2021.

[38] X. Li, Z. Yu, P. Liu, Z. Shan, and Z. Meng, "Experimental investigation of stochastic mechanical behavior of cement emulsified asphalt mortar under monotonic compression," Applied Sciences, vol. 10, no. 8, p. 2860, 2020.

[39] X. Li, Z. Shan, Z. Yu, J. Gao, and J. Mao, "Stochastic constitutive relationship of self-compacting concrete under uniaxial compression," Advances in Civil Engineering, vol. 2018, pp. 1-14, 2018.

[40] China academy of building research, Load Code for the Design of Building Structures, China architecture and building press, Beijing, China, (in Chinese), 2012. 